\title{
Body image and eating patterns among adolescents
}

Maria del Mar Bibiloni ${ }^{1,2}$, Jordi Pich ${ }^{1,2}$, Antoni Pons ${ }^{1,2}$ and Josep A Tur ${ }^{1,2^{*}}$

\begin{abstract}
Background: Data on the association between body self-perception and eating patterns among adolescents are scarce. This study assessed the association between body image and eating patterns among normal-weight, overweight and obese adolescents.

Methods: A cross-sectional survey ( $n=1231 ; 12-17$ years old) was carried out in the Balearic Islands, Spain. Anthropometry, body image, socio-economic determinants, and food consumption were studied.

Results: Fifty-one percent of boys and sixty percent of girls that wished to be thinner had less than or equal to 3 eating occasions per day. Overfat girls that wish to be thinner skipped breakfast more frequently than normal-fat girls. Overfat boys and girls that wished a thinner body reported lower consumption of several food groups than normal-fat adolescents and overfat boys satisfied with their own body image (i.e. breakfast cereals, pasta and rice dishes, other oils and fats, high fat foods, soft drinks and chocolates in boys; and dairy products and chocolates in girls).A restriction of Western diet foods and energy intake was associated with a wish to be thinner among overfat adolescents.
\end{abstract}

Conclusions: Many overfat boys were satisfied with their body image while practically all overfat girls reported wishing a thinner body. Meal patterns and food consumption were associated with body dissatisfaction and overfat status among adolescents.

Keywords: BMI, FMI, Body image, Adolescents, Food intake, Eating patterns

\section{Background}

Adolescence is a transitional stage and many changes take place at physiological and behavioural levels. Among adolescents, the prevalence of overweight and obesity has risen greatly worldwide [1,2], and among the Balearic Islands' adolescents the prevalence of overweight (19.9\% boys and $15.5 \%$ girls) and obesity (12.7\% boys and $8.5 \%$ girls) should take into consideration [3]. Adolescent obesity is associated with significant immediate and long term health risks, and also predicts obesity in adulthood and increase risk of adult morbidity and mortality $[1,2]$.

A pattern of healthy eating habits and adequate physical activity during adolescence reduces the risk of major chronic diseases [4-6]. However, a high intake of total

\footnotetext{
* Correspondence: pep.tur@uib.es

${ }^{1}$ Research Group on Community Nutrition and Oxidative Stress, Universitat de les Illes Balears, Guillem Colom Bldg, Campus, E-07122 Palma de Mallorca, Spain

${ }^{2}$ CIBERobn (Fisiopatología de la Obesidad y la Nutrición) CB12/03/30038, E-07122 Palma de Mallorca, Spain
}

\section{() Biomed Central}

(c) 2013 Bibiloni et al.; licensee BioMed Central Ltd. This is an open access article distributed under the terms of the Creative Commons Attribution License (http://creativecommons.org/licenses/by/2.0), which permits unrestricted use, distribution, and reproduction in any medium, provided the original work is properly cited. fat, saturated fat and sodium, a low intake of vitamins and minerals, and a low consumption of fruits and vegetables are usual dietary patterns among adolescents [7-9], and only a small proportion of the Balearic Islands' adolescents met the requirements of dietary fibre, folate, iodine, total fat, saturated fat, polyunsaturated fatty acid, total carbohydrate, and fruit and vegetables [10].

It has been pointed out that people with higher relative weight usually underreported their food intake [11]. However, controversial results have been reported on the association between food consumption and overweight and obesity, which can be attributed to overestimation of healthy foods and underestimation of unhealthy foods. Moreover, to avoid high-calorie foods has been associated with attempts to lose weight in adolescents [12,13].

Body image is a multidimensional construct central to emotional well-being in which the attitudinal component is satisfaction with body size, a factor associated with self-esteem [14]. During this period, the self-evaluation 
of body image and social patterns of beauty are factors that have a strong influence on eating habits [15-17]. Currently, there is a lack of data referring to the association between body self-perception and eating patterns among overweight and obesity in adolescents. Therefore these data are needed in order to design interventions to improve an effective nutrition and weight counselling among adolescents.

The aim of this study was to assess the association between body image and eating patterns among normalweight, overweight and obese adolescents.

\section{Methods}

\section{Study design}

The study is a population-based cross-sectional nutritional survey carried out (2007-2008) in the Balearic Islands (Spain), a Mediterranean region.

\section{Selection of participants, recruitment and approval}

A multicenter study was performed on Balearic Islands' adolescents aged 12-17 years. The population was selected by means of a multiple-step, simple random sampling, first taking into account the location (Palma de Mallorca, Calvià, Inca, Manacor, Maó, Eivissa, Llucmajor, Santa Margalida, S'Arenal, Sant Jordi de Ses Salines) and then by random assignment of the schools within each city. Sample size was stratified by age and sex. The socioeconomic variable was considered to be associated to geographical location and type of school. As the selection of schools was done by random selection and fulfilling quota, this variable was also considered to be randomly assigned.

To calculate a representative number of adolescents, the variable BMI with the greatest variance for this age group from the data published in the literature at the time the study was selected [18]. Sampling was determined for the distribution of this variable; and a confidence interval (CI) was established at $95 \%$ with an error \pm 0.25 . The total number of subjects (1500) was uniformly distributed in the cities and proportionally distributed by sex and age. Exclusion criteria used were: type 2 diabetes, pregnancy, alcohol or drug abuse, and non-directly related nutritional medical conditions.

The sample was oversized to prevent information loss and done when necessary to do the fieldwork in complete classrooms. In each school, classrooms were randomly selected among those of the same grade or level, and all the adolescents of one classroom were proposed to participate in the survey. A letter about the nature and purpose of the study informed parents or legal tutors and after receiving their written consent, the adolescents were considered for inclusion in the study. All responses to the questionnaires were filled in by adolescents. After finishing the field study, the adolescents who did not fulfil the inclusion criteria were excluded. Finally, the sample was adjusted by a weight factor in order to balance the sample in accordance to the distribution of the Balearic Islands' population and to guarantee the representativeness of each of the groups, already defined by the previously mentioned factors (age and sex). The final number of subjects included in the study was 1231 adolescents (82\% participation). Reasons for not participate were (a) the subject declined to be interviewed, and (b) the parents did not authorize the interview.

This study was conducted according to the guidelines laid down in the Declaration of Helsinki, and all procedures involving human subjects were approved by the Balearic Islands' Ethics Committee (Palma de Mallorca, Spain).

\section{Anthropometry measurements}

Height was determined using a mobile anthropometer (Kawe 44444, Asperg, Germany) measured to the nearest millimetre, with the subject's head in the Frankfurt plane. Body weight was determined to the nearest $100 \mathrm{~g}$ using a digital scale (Tefal, sc9210, Rumilly, France), and subjects were weighed in bare feet and light underwear. Waist circumference (WC) and hip circumference $(\mathrm{HC})$ were measured using a non-stretchable measuring tape (Kawe, 43972, France). The subjects were asked to stand erect in a relaxed position with both feet together on a flat surface. WC was measured as the smallest horizontal girth between the costal margins and the iliac crests at minimal respiration with measurements taken to the nearest $0.1 \mathrm{~cm}$. HC was taken as the greatest circumference at the level of greater trochanters (the widest portion of the hip) on both sides with measurements taken to the nearest $0.1 \mathrm{~cm}$. Triceps and subscapular skinfold thickness (ST) were measured on the right side of the using a Holtain skinfold caliper (Tanner/Whitehouse, Crosswell, Crymych, UK), and a mean of three measurements was used. Body fat percentage (\%BF) was calculated from triceps and subscapular ST according to Slaughter et al. [19]. This equation has been proposed as the most accurate for estimation of \%BF from ST in this particular population of adolescents [20]. Height and weight measures were used to calculate body mass index $\left(\mathrm{BMI}, \mathrm{kg} / \mathrm{m}^{2}\right)$ and $\mathrm{WC}$ and height were used to calculate waist-to-height ratio (WHtR). \%BF and height were used to calculate fat mass index (FMI; $\mathrm{kg} / \mathrm{m}^{2}$ ).

\section{Defining overweight and obesity}

Adolescents were age- and sex-specific classified using the BMI cut-offs developed and proposed by the International Obesity Task Force (IOTF) [21] and Cole et al. [22] definitions, and then subjects were classified as normal-fat and overfat according to their FMI using sexspecific cut-offs proposed for adolescents: $4.58 \mathrm{~kg} / \mathrm{m}^{2}$ in 
boys and $7.76 \mathrm{~kg} / \mathrm{m}^{2}$ in girls [23]. Thus, adolescents were classified into five weight and fat groups as following:

1) Underweight and normal-weight normal-fat (BMI for age and sex $<$ P85; FMI $<4.58 \mathrm{~kg} / \mathrm{m}^{2}$ in boys, FMI $<7.76 \mathrm{~kg} / \mathrm{m}^{2}$ in girls).

2) Normal-weight overfat (BMI for age and sex < P85; FMI $\geq 4.58 \mathrm{~kg} / \mathrm{m}^{2}$ in boys, FMI $\geq 7.76 \mathrm{~kg} / \mathrm{m}^{2}$ in girls).

3) Overweight normal-fat (BMI for age and sex $>$ P85 and $<$ P97; FMI $<4.58 \mathrm{~kg} / \mathrm{m}^{2}$ in boys, FMI $<7.76 \mathrm{~kg} / \mathrm{m}^{2}$ in girls).

4) Overweight overfat (BMI for age and sex equivalent to $>$ P85 and $<$ P97; FMI $\geq 4.58 \mathrm{~kg} / \mathrm{m}^{2}$ in boys, FMI $\geq 7.76 \mathrm{~kg} / \mathrm{m}^{2}$ in girls).

5) Obesity (BMI for age and sex $\geq$ P97).

\section{Body image}

Perceived body image was measured using the Stunkard scale [24], which consists of silhouette drawings ranging from 1 to 9 with monotonic increments in overweight percentage where 1 is the leanest and 9 is the heaviest. Separate figures for boys and girls were used. Participants were asked to identify of the 9 body figures: (a) 'Which silhouette looks most like yourself?' and (b) 'Which silhouette would you like to look like?' The difference between perceived body image and wished body image was used to determine the level of dissatisfaction with current body image. Values other than zero represent dissatisfaction with perceived body image. A positive value was indicative of the participant's wish to be thinner than his/her perceived current size, while a negative value reflected the participant's wish to be thicker than his/her current perceived size $[25,26]$.

\section{Dietary assessment}

Dietary assessment was assessed by using a validated [27] semi-quantitative food-frequency questionnaire (FFQ) covering 145 items (118 of the original validated FFQ plus the most characteristic Balearic Islands foods in order to make easy the interviewee answer). The FFQ evaluated average consumption over the past year. To prevent seasonal variations, the questionnaire was administered in the warm season (May-September) and in the cold season (November-March). Food consumption frequency was based on times that food items were consumed (per day, week or month). Consumption $<1 /$ month was considered no consumption. Daily food consumption (g/d) was determined by dividing the reported amount (g) of food consumed by the frequency of intake (d). Volumes and portion sizes were reported in natural units, household measures or with the aid of a manual of sets of photographs [28]. The 145 foods items from the FFQ were reduced to twenty-eight food groups, which may have practical importance in daily diet and clinical practice with Mediterranean youths [29,30].

Well-trained dieticians administered, verified and quantified all dietary questionnaires. To estimate volumes and portion sizes, the household measures found in the subjects' own homes were used. Conversion of food into nutrients was done using a computer program (ALIMENTA ${ }^{\oplus}$, NUCOX, Palma, Spain) based on Spanish [31,32] and European [33] food composition tables and complemented with food composition data available for Majorcan food items [34]. As an identification of misreporters: an energy intake (EI)/basal metabolic rate (BMR) ratio of $<0.92$ (boys) and $<0.85$ (girls) was considered to represent underreporters [35], and an EI:BMR $\geq 2.4$ as overreporters [36].

\section{Assessment of meal patterns}

The number of daily meals and snacks was calculated from the total eating occasions that participants declared among the following: breakfast, mid-morning snack, lunch, mid-afternoon snack, dinner, before going to sleep, others. Three groups of eating frequency were considered: $\leq 3,4$ and $\geq 5$ times/d. Information about breakfast habit (yes; occasionally; no) was also collected.

\section{Assessment of socioeconomic factors}

Socio-demographic factors were recorded using a questionnaire that included age group, parental education level (according to years and education type: low, <6 years; medium, 6-12 years; high, >12 years), and parental profession level (based on the occupation of parents and classified as low, medium and high, according to the Spanish Society of Epidemiology [37].

\section{Statistics}

Analyses were performed with Statistical Package for the Social Sciences version 21.0 (SPSS, Inc., Chicago, IL, USA). Significant differences in energy intake were calculated by means of ANOVA, and significant differences in prevalence by means of $X^{2}$. We further applied multiple logistic regression analysis evaluating the association between body composition taking into account body image (normal-fat vs. overfat desiring to be thinner vs. overfat satisfied) with consumption frequencies of several food groups adjusted for potential confounders (age, parental educational level, parental socio-economic status, breakfast habit, number of daily meals and snacks). Level of significance for acceptance was $P<0.05$.

\section{Results}

Body image according to body composition (BMI and FMI)

Table 1 shows the prevalence of normal-weight, overweight and obesity (BMI) according to overall adiposity (FMI) and desire to change weight. The three body weight 
Table 1 Prevalence (\%) of normal-weight, overweight and obesity associated with desiring for body weight change according to body weight (BMI) and adiposity (FMI) among Balearic Islands adolescents

\begin{tabular}{|c|c|c|}
\hline Categories & Boys $(n=574)$ & Girls $(n=657)$ \\
\hline \multicolumn{3}{|c|}{ 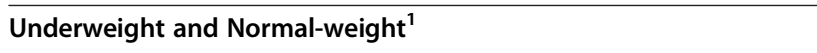 } \\
\hline Normal-fat ${ }^{4}$ & 68.3 & 77.4 \\
\hline Wants thinner body & 14.3 & 47.8 \\
\hline Remain the same body & 46.6 & 42.9 \\
\hline Wants thicker body & 39.1 & 9.3 \\
\hline Overfat $^{5}$ & 4.0 & 0.5 \\
\hline Wants thinner body & 61.9 & - \\
\hline Remain the same body & 38.1 & - \\
\hline Wants thicker body & 0.0 & - \\
\hline \multicolumn{3}{|l|}{ Overweight $^{2}$} \\
\hline Normal-fat ${ }^{4}$ & 3.6 & 9.3 \\
\hline Wants thinner body & 52.6 & 88.7 \\
\hline Remain the same body & 36.8 & 11.3 \\
\hline Wants thicker body & 10.5 & 0.0 \\
\hline Overfat $^{5}$ & 17.6 & 7.1 \\
\hline Wants thinner body & 82.4 & 93.6 \\
\hline Remain the same body & 16.5 & 6.4 \\
\hline Wants thicker body & 1.1 & 0.0 \\
\hline Obesity $^{3}$ & 6.5 & 5.8 \\
\hline Wants thinner body & 97.0 & 100.0 \\
\hline Remain the same body & 3.0 & 0.0 \\
\hline Wants thicker body & 0.0 & 0.0 \\
\hline
\end{tabular}

Abbreviations: $B M I$ body mass index; $F M I$ fat mass index. ${ }^{1}$ Underweight and normal-weight (BMl-for age and sex $<$ P85), ${ }^{2}$ overweight (BMI-for-age and sex >P85 and $<$ P97) and ${ }^{3}$ obesity (BMl-for-age and sex $\geq$ P97) as previously defined $[21,22]$. ${ }^{4}$ Normal-fat (boys: FMI $<4.58 \mathrm{~kg} / \mathrm{m}^{2}$; girls: $\mathrm{FMI}<7.76 \mathrm{~kg} / \mathrm{m}^{2}$ ) and ${ }^{5}$ overfat (boys: $\mathrm{FMl} \geq 4.58 \mathrm{~kg} / \mathrm{m}^{2}$; girls: $\mathrm{FMl} \geq 7.76 \mathrm{~kg} / \mathrm{m}^{2}$ ) defined according to the previously proposed cut-offs [20]. Since the prevalence of overfat girls satisfied with own body shape was only $0.5 \%(n=3)$ this group was not considered in this analysis.

groups obtained by the IOTF cut-offs (underweight and normal-weight, overweight, and obesity) were subgrouped according to presence or absence of overfat. Adolescents were classified into five groups as following: $73.2 \%$ underweight and normal-weight normal-fat, $2.1 \%$ normal-weight overfat, $6.7 \%$ overweight normal-fat, $11.9 \%$ overweight overfat and $6.1 \%$ obesity. The wish to change weight was assessed for each subgroup. Among boys, 39.1\% of underweight and normal-weight normal-fat and $10.5 \%$ of overweight normal-fat adolescents reported to wish a thicker body shape; whereas $61.9 \%$ of normal-weight overfat, $82.4 \%$ of overweight overfat and $97.0 \%$ of obese boys reported to wish a thinner body shape. Among girls, around half of underweight and normal-weight normal-fat adolescents $(47.8 \%)$ reported to wish a thinner body shape which increased according to the presence of excessive weight and/or excessive BF.

\section{Meal patterns according to body composition and body image}

Table 2 shows associations between meal patterns and body composition taking into account satisfaction with their body shape (normal-fat vs. overfat wishing to be thinner vs. overfat satisfied). It is important to note that most of overfat girls (96.6\%) wished to be thinner, and an inverse association with number of daily meals and snacks and breakfast habit was found among them. Overfat boys that wished a thinner body shape $(82.8 \%)$ also were more likely to have $\leq 3$ eating occasions per day $(50.8 \%)$ than their overfat satisfied and normal-fat counterparts.

\section{Food consumption according to body composition and body image}

Associations between the food consumption and individual items and satisfaction with own body shapes were also evaluated (Table 3). Overfat boys that wished to be thinner were less likely to consume breakfast cereals, pasta and rice dishes, other oils and fats, high fat foods, soft drinks and chocolates than their satisfied and normalfat counterparts. Compared with normal-fat girls, those who were overfat also reported to consume dairy desserts and chocolates with less frequency.

When energy intake (EI) was calculated, overfat adolescents (37\%) misreported their EI more often than normalfat peers $(10 \%)$. Overfat adolescents who wished to be thinner showed a significant $(P<0.001)$ lower EI than overfat adolescents satisfied with their body shape and normal-fat adolescents, and overfat adolescents wishing to be thinner also showed significant $(P<0.001)$ lower energy intake from saturated fat acids than normal-fat peers (Table 4).

Multiple logistic regression analysis (after adjustment by age, parental educational level, parental socio-economic status, breakfast habit, number of daily meals and snacks) showed that overfat that wished to be thinner were less likely to frequently eat red meat, pasta and rice dishes and other oils and fats than their satisfied and normal-fat counterparts (Table 5).

\section{Discussion}

The main findings of this study were: (1) many overfat boys were satisfied with their body image while practically all overfat girls reported to wish a thinner body; and (2) meal patterns and food consumption were associated with body dissatisfaction among overfat adolescents. In both genders, overfat adolescents that wished a thinner body were more likely to declare $\leq 3$ eating occasions per day than normal-fat adolescents, and also than overfat boys satisfied with their own body image. Overfat girls 
Table 2 Meal patterns by body composition taking into account body image among Balearic Islands adolescents

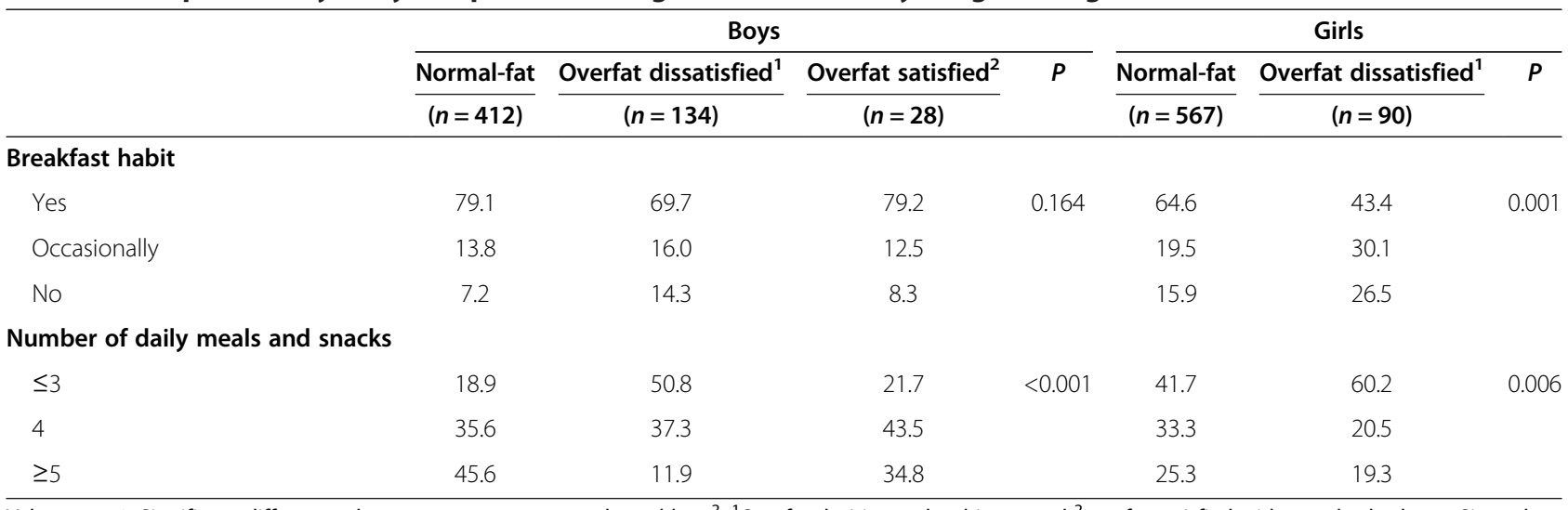

Values are \%. Significant differences between groups were evaluated by $x^{2}$. ${ }^{1}$ Overfat desiring to be thinner and ${ }^{2}$ overfat satisfied with own body shape. Since the prevalence of overfat girls satisfied with own body shape was only $0.5 \%(n=3)$ this group was not considered in this analysis.

that wish to be thinner skipped breakfast more frequently than normal-fat girls. Overfat boys and girls that wished a thinner body reported lower consumption of several food groups than normal-fat adolescents and overfat boys satisfied with their own body image (i.e. breakfast cereals, pasta and rice dishes, other oils and fats, high fat foods, soft drinks and chocolates in boys; and dairy products and chocolates in girls). Consequently, the overfat adolescents studied misreported their energy intake more often than normal-fat peers, and overfat adolescents dissatisfied with their body shape showed lower energy intake than normal-fat and satisfied peers. Restrictive eating practices related to a preoccupation with a slim image have been also reported among adolescents [38-40].

\section{Gender differences in body satisfaction}

Boys and girls perceive their bodies in a different way [41]. It has been extensively previously reported that the current ideal male body is lean but highly muscular, characterised by a "well-developed chest and arms, with wide shoulders tapering down to a narrow waist" [42]. Thus, whereas boys with lower BMI and BF preferred a stronger muscular body, girls showed a preference for a slim body shape $[41,43]$. However, boys with elevated adiposity also showed a preference for a slim body shape; in fact, they have been most likely to have negative feelings about their bodies [44]. It has been suggested that adolescents who are heavy and perceive themselves as overfat may have actively tried to lose weight [45], whereas adolescents who do not perceive themselves as heavy raise concerns may be less motivated to take steps to lose weight [46]. Moreover, despite that adolescents denigrate overweight and obesity, a decrease in body dissatisfaction has been suggested in studies among young people [47].
It has been also recognized that to be worried about body image is especially acute in puberty [48], but also that body image is an important target of intervention to improve subjective health in adolescence [49]. It has been pointed out that some level of body dissatisfaction may be beneficial for individuals with average or aboveaverage weight, as it may lead to healthy weight management behaviours such as increased intake of fruits and vegetables and regular physical activity $[50,51]$. To understand how body shape satisfaction affects meal patterns, food preferences and the overall adolescent diet is a key issue for the development of strategies aimed at influencing dietary behaviour. Accordingly, findings from the present study will be useful to understand relationships between body image and eating patterns.

\section{Meal patterns and food consumption are associated with body image}

A previous study reported that normal-fat adolescents were more likely to follow a Western dietary pattern than a Mediterranean dietary pattern, and the wish to have a thinner body shape was associated with a low consumption of the Western dietary pattern [52]. Moreover, it has been also reported that parallel to the omission of meals, it may be possible that overfat adolescents that wished to be thinner avoided the consumption of several foods to counteract being overfat; boys and girls have been reported to avoid sweets and salty snack consumption to counteract being overweight [3]. Accordingly, a study conducted among 3055 Massachusetts high school students (aged $16 \pm 1.2$ years) found that adolescents attempted to lose weight consumed fewer servings of fatty foods, but they did not increase fruit and vegetable consumption; to lose weight, they also ate few servings of desserts, whereas to gain weight they ate more servings of these foods [16]. 
Table 3 Food consumption by body composition taking into account body image among Balearic Islands adolescents

\begin{tabular}{|c|c|c|c|c|c|c|c|c|}
\hline \multirow{3}{*}{ Food groups } & \multirow{3}{*}{$\begin{array}{l}\text { Frequency } \\
\text { categories }^{3}\end{array}$} & \multicolumn{4}{|c|}{ Boys } & \multicolumn{3}{|c|}{ Girls } \\
\hline & & Normal-fat & Overfat dissatisfied $^{1}$ & Overfat satisfied $^{2}$ & $P$ & Normal-fat & Overfat dissatisfied $^{1}$ & $P$ \\
\hline & & $(n=412)$ & $(n=134)$ & $(n=28)$ & & $(n=567)$ & $(n=90)$ & \\
\hline \multicolumn{9}{|l|}{ Dairy products } \\
\hline Milk & $\geq 7 \mathrm{t} / \mathrm{w}$ & 79.9 & 76.5 & 76.5 & 0.788 & 66.4 & 55.3 & 0.128 \\
\hline Yogurt and cheese & $\geq 7 \mathrm{t} / \mathrm{w}$ & 67.1 & 64.7 & 70.6 & 0.879 & 62.4 & 59.6 & 0.700 \\
\hline Dairy desserts & $\geq 2 \mathrm{t} / \mathrm{w}$ & 77.2 & 77.9 & 82.4 & 0.880 & 65.2 & 46.8 & 0.013 \\
\hline \multicolumn{9}{|l|}{ Meat } \\
\hline Red meat & $\geq 2 \mathrm{t} / \mathrm{w}$ & 56.3 & 41.8 & 64.7 & 0.067 & 44.8 & 34.8 & 0.193 \\
\hline Poultry and rabbit & $\geq 2 \mathrm{t} / \mathrm{w}$ & 15.2 & 14.7 & 11.8 & 0.925 & 14.8 & 13.0 & 0.751 \\
\hline \multirow[t]{3}{*}{ Sausages } & $\geq 5 \mathrm{t} / \mathrm{w}$ & 52.4 & 52.2 & 58.8 & 0.874 & 47.6 & 45.7 & 0.804 \\
\hline & $2-4 t / w$ & 27.4 & 28.4 & 29.4 & 0.975 & 25.2 & 19.6 & 0.401 \\
\hline & $\leq 4 \mathrm{t} / \mathrm{m}$ & 20.1 & 19.4 & 11.8 & 0.699 & 27.3 & 34.8 & 0.279 \\
\hline Fish and seafood & $\geq 2 \mathrm{t} / \mathrm{w}$ & 17.4 & 25.4 & 17.6 & 0.317 & 15.7 & 6.5 & 0.096 \\
\hline Eggs & $\geq 2 \mathrm{t} / \mathrm{w}$ & 36.5 & 34.3 & 29.4 & 0.811 & 22.4 & 23.9 & 0.816 \\
\hline Legumes & $\geq 2 \mathrm{t} / \mathrm{w}$ & 19.7 & 22.1 & 5.9 & 0.317 & 17.5 & 10.6 & 0.234 \\
\hline \multicolumn{9}{|c|}{ Cereals, grains and products } \\
\hline Bread & $\geq 7 \mathrm{t} / \mathrm{w}$ & 84.8 & 88.2 & 88.2 & 0.727 & 82.1 & 83.0 & 0.877 \\
\hline Breakfast cereals & $\geq 5 \mathrm{t} / \mathrm{w}$ & 53.3 & 35.3 & 47.1 & 0.028 & 30.1 & 31.9 & 0.799 \\
\hline Biscuits & $\geq 5 \mathrm{t} / \mathrm{w}$ & 22.8 & 17.6 & 17.6 & 0.594 & 23.0 & 14.9 & 0.205 \\
\hline Pasta and rice dishes & $\geq 5 \mathrm{t} / \mathrm{w}$ & 22.8 & 11.8 & 35.3 & 0.048 & 15.6 & 25.5 & 0.083 \\
\hline Pizza & $\geq 2 \mathrm{t} / \mathrm{w}$ & 18.7 & 10.3 & 11.8 & 0.213 & 11.0 & 14.9 & 0.429 \\
\hline
\end{tabular}

Fruits

\begin{tabular}{|c|c|c|c|c|c|c|c|c|}
\hline Fresh fruits & $\geq 2 /$ day & 30.1 & 32.4 & 29.4 & 0.932 & 30.8 & 31.9 & 0.876 \\
\hline Fruit juices & $\geq 7 \mathrm{t} / \mathrm{w}$ & 54.0 & 44.1 & 52.9 & 0.341 & 50.6 & 51.1 & 0.949 \\
\hline Canned fruits & $\geq 2 \mathrm{t} / \mathrm{w}$ & 9.3 & 10.3 & 5.9 & 0.855 & 4.8 & 6.4 & 0.641 \\
\hline Vegetables & $\geq 2 /$ day & 7.3 & 7.4 & 5.9 & 0.976 & 12.9 & 14.9 & 0.696 \\
\hline Nuts & $\geq 2 \mathrm{t} / \mathrm{w}$ & 39.4 & 32.4 & 41.2 & 0.538 & 24.8 & 23.4 & 0.830 \\
\hline Potatoes and tubercles & $\geq 2 \mathrm{t} / \mathrm{w}$ & 42.9 & 47.1 & 41.2 & 0.807 & 33.3 & 29.8 & 0.623 \\
\hline \multicolumn{9}{|l|}{ Fats } \\
\hline Olive oil & $\geq 7 \mathrm{t} / \mathrm{w}$ & 51.7 & 41.8 & 47.1 & 0.333 & 54.0 & 52.2 & 0.809 \\
\hline Other oils and fats & $\geq 2 \mathrm{t} / \mathrm{w}$ & 41.0 & 23.9 & 35.3 & 0.033 & 36.7 & 30.4 & 0.399 \\
\hline \multirow[t]{3}{*}{ High fat foods } & $\geq 5 \mathrm{t} / \mathrm{w}$ & 49.7 & 31.3 & 47.1 & 0.026 & 38.1 & 26.1 & 0.108 \\
\hline & $2-4 t / w$ & 24.3 & 32.8 & 41.2 & 0.138 & 28.4 & 32.6 & 0.550 \\
\hline & $\leq 4 \mathrm{t} / \mathrm{m}$ & 26.0 & 35.8 & 11.8 & 0.093 & 33.5 & 41.3 & 0.288 \\
\hline \multicolumn{9}{|l|}{ Drinks } \\
\hline \multirow[t]{3}{*}{ Soft drinks } & $\geq 5 \mathrm{t} / \mathrm{w}$ & 59.4 & 40.3 & 52.9 & 0.018 & 41.8 & 43.5 & 0.827 \\
\hline & $2-4 t / w$ & 10.8 & 11.9 & 17.6 & 0.672 & 11.1 & 6.5 & 0.340 \\
\hline & $\leq 4 \mathrm{t} / \mathrm{m}$ & 29.9 & 47.8 & 29.4 & 0.019 & 47.1 & 50.0 & 0.709 \\
\hline Tea and coffee & $\geq 2 \mathrm{t} / \mathrm{w}$ & 10.8 & 13.4 & 23.5 & 0.258 & 16.7 & 13.0 & 0.527 \\
\hline Alcoholic beverages & $\geq 1 \mathrm{t} / \mathrm{w}$ & 8.9 & 5.9 & 11.8 & 0.637 & 3.7 & 4.3 & 0.845 \\
\hline \multicolumn{9}{|l|}{ Sweets } \\
\hline \multirow[t]{3}{*}{ Sweets } & $\geq 5 \mathrm{t} / \mathrm{w}$ & 73.6 & 73.1 & 64.7 & 0.723 & 79.2 & 67.4 & 0.067 \\
\hline & $2-4 t / w$ & 14.6 & 11.9 & 17.6 & 0.787 & 13.0 & 19.6 & 0.214 \\
\hline & $\leq 4 \mathrm{t} / \mathrm{m}$ & 11.8 & 14.9 & 17.6 & 0.642 & 7.9 & 13.0 & \\
\hline
\end{tabular}


Table 3 Food consumption by body composition taking into account body image among Balearic Islands adolescents (Continued)

\begin{tabular}{|c|c|c|c|c|c|c|c|c|}
\hline \multirow[t]{3}{*}{ Chocolates } & $\geq 5 \mathrm{t} / \mathrm{w}$ & 21.9 & 9.0 & 41.2 & 0.006 & 19.9 & 8.7 & 0.065 \\
\hline & $2-4 \mathrm{t} / \mathrm{w}$ & 11.5 & 13.4 & 5.9 & 0.681 & 11.8 & 6.5 & 0.284 \\
\hline & $\leq 4 \mathrm{t} / \mathrm{m}$ & 66.7 & 77.6 & 52.9 & 0.088 & 68.4 & 84.8 & 0.021 \\
\hline
\end{tabular}

Abbreviations: $t / w$ times/week, $t / m$ times/month. Values are $\%$. Significant differences between groups were evaluated by $x^{2}$. ${ }^{1}$ Overfat desiring to be thinner and ${ }^{2}$ overfat satisfied with own body shape. ${ }^{3}$ According to previously defined food consumption cut-offs [29,30]. Since the prevalence of overfat girls satisfied with own body shape was only $0.5 \%(n=3)$ this group was not considered in this analysis.

Previous findings showed that girls tried to lose weight eating few servings of meat, fries, chips, and dessert foods, whereas to gain weight they consumed few servings of fruit and green salad and increased the consumption of fries and chips [16]. A study conducted among 1220 Costa Rican adolescents (aged 12-18 years) showed that body image was associated with a high consumption of high-calcium and saturated fat foods, iron rich foods, and fruits and vegetables [53]. Our results suggest that adolescents that wish a thinner body decreased consumption of typical-Western-diet foods, but they did not increase consumption of fruits and vegetables, which may reflect a diet restriction rather than eating healthier food as a method to lose weight.

Overall, the current results highlight the importance of body image on adolescent nutritional habits and food choices. Particularly, a restriction of typical-Western-diet foods is associated with a wish to be thinner among overfat adolescents. A task for future research could be to include assessments of body image to better understand the prospective and concurrent contributions of body image to food consumption patterns among normalweight, overweight and obesity adolescents. Our data could be useful to practitioners in targeting educational messages for individuals' specific eating patterns and to community planners in encouraging the availability of a healthy dietary pattern.

\section{Conclusions}

Many overfat boys were satisfied with their body image while practically all overfat girls reported wishing a thinner body. Meal patterns and food consumption were associated with body dissatisfaction and overfat status among adolescents.

\section{Strengths and limitations}

This study has some limitations. The difficulties for assessing food intake among young people are well known but it should not serve as a deterrent to pursue this line of research. Moreover, BF was calculated using Slaughter et al. equations [19], which have been previously reported [20]. This study did not take into account pubertal development; however, a previous study [51] classified adolescents according to their pubertal stage and divided boys in two groups: pubertal (12-14 y.o.) and post-pubertal (15-17 y.o.). Moreover, it should be noted that we cannot ignore that adolescents that wish to be thinner could overestimate healthy foods consumption and underestimate unhealthy foods consumption; it has been well documented that people with high relative weight usually underreported their food intake [11]. Finally, we cannot infer causality because of the crosssectional design of the study.

This study also has several strengths. New data is provided about the association between body image and food consumption patterns among adolescents according to their body composition. Specifically, it provides data evaluating the association between food consumption and dissatisfaction with overfat status among adolescents, which is scarce in this age group. Moreover, most of the previous studies in adolescents analyzed differences in perception of body image and weight concerns according to gender [49], ethnic and social differences [41], and overweight and obesity status, showing that

Table 4 Energy intake (mean values \pm SD) by body composition taking into account body image among Balearic Islands' adolescents

\begin{tabular}{|c|c|c|c|c|c|c|c|}
\hline & \multicolumn{4}{|c|}{ Boys } & \multicolumn{3}{|c|}{ Girls } \\
\hline & Normal-fat & Overfat dissatisfied $^{1}$ & Overfat satisfied $^{2}$ & $P$ & Normal-fat & Overfat dissatisfied $^{1}$ & $P$ \\
\hline & $\overline{(n=412)}$ & $(n=134)$ & $(n=28)$ & & $\overline{(n=567)}$ & $(n=90)$ & \\
\hline Energy intake $(\mathrm{kcal} / \mathrm{d})^{3}$ & $2378 \pm 793$ & $1849 \pm 603$ & $2361 \pm 894$ & $<0.001$ & $1850 \pm 606$ & $1578 \pm 607$ & $<0.001$ \\
\hline Energy from AGS (\%) ${ }^{4}$ & $13.7 \pm 3.8$ & $12.6 \pm 3.6$ & $14.0 \pm 4.9$ & $<0.001$ & $13.5 \pm 4.1$ & $12.7 \pm 3.9$ & $<0.001$ \\
\hline
\end{tabular}

${ }^{1}$ Overfat desiring to be thinner and ${ }^{2}$ overfat satisfied with own body shape. Since the prevalence of overfat girls satisfied with own body shape was only $0.5 \%$ $(\mathrm{n}=3)$ this group was not considered in this analysis. ${ }^{3}$ Significant differences between groups were evaluated by ANOVA. ${ }^{4}$ Significant differences between groups were evaluated by $x^{2}$. 
Table 5 Association between body image and food consumption among adolescents

\begin{tabular}{|c|c|c|c|}
\hline \multirow[b]{2}{*}{ Food groups ${ }^{1}$} & \multirow[b]{2}{*}{ Frequency categories } & \multicolumn{2}{|c|}{ Overfat desiring thinner body vs. overfat satisfied and normal-fat ${ }^{2}$} \\
\hline & & Boys & Girls \\
\hline \multicolumn{4}{|l|}{ Dairy products } \\
\hline Milk & $\geq 7$ t/w vs. $<7$ t/w (ref.) & $0.49(0.19-1.29)$ & $0.98(0.41-2.34)$ \\
\hline Yogurt and cheese & $\geq 7 \mathrm{t} / \mathrm{w}$ vs. $<7 \mathrm{t} / \mathrm{w}$ (ref.) & $1.39(0.62-3.12)$ & $1.04(0.43-2.50)$ \\
\hline Dairy desserts & $\geq 2$ t/w vs. 2 t/w (ref.) & $2.39(0.92-6.18)$ & $0.30(0.13-0.70)^{* *}$ \\
\hline \multicolumn{4}{|l|}{ Meat } \\
\hline Red meat & $\geq 2$ t/w vs. 2 t/w (ref.) & $0.35(0.16-0.79)^{*}$ & $0.64(0.27-1.53)$ \\
\hline Poultry and rabbit & $\geq 2$ t/w vs. 2 t/w (ref.) & $1.93(0.58-6.47)$ & $0.80(0.23-2.75)$ \\
\hline \multirow[t]{3}{*}{ Sausages } & $\geq 5 \mathrm{t} / \mathrm{w}$ vs. $\leq 4 \mathrm{t} / \mathrm{m}$ (ref.) & $1.61(0.60-4.32)$ & $1.12(0.46-2.74)$ \\
\hline & $2-4$ t/w vs. $\leq 4$ t/m (ref.) & $1.57(0.57-4.35)$ & $0.67(0.23-1.98)$ \\
\hline & $\leq 4 \mathrm{t} / \mathrm{m}$ (ref.) & & \\
\hline Fish and seafood & $\geq 2$ t/w vs. 2 t/w (ref.) & $2.24(0.84-5.99)$ & $0.29(0.07-1.22)$ \\
\hline Eggs & $\geq 2$ t/w vs. 2 t/w (ref.) & $0.79(0.34-1.88)$ & $1.29(0.51-3.28)$ \\
\hline Legumes & $\geq 2$ t/w vs. 2 t/w (ref.) & $1.27(0.45-3.57)$ & $0.49(0.13-1.76)$ \\
\hline \multicolumn{4}{|c|}{ Cereals, grains and products } \\
\hline Bread & $\geq 7$ t/w vs. $<7$ t/w (ref.) & $2.99(0.90-9.98)$ & $1.02(0.34-3.01)$ \\
\hline Breakfast cereals & $\geq 5$ t/w vs. $<5$ t/w (ref.) & $0.56(0.26-1.19)$ & $1.42(0.59-3.44)$ \\
\hline Biscuits & $\geq 5 \mathrm{t} / \mathrm{w}$ vs. $<5 \mathrm{t} / \mathrm{w}$ (ref.) & $0.90(0.43-1.90)$ & $1.09(0.48-2.45)$ \\
\hline Pasta and rice dishes & $\geq 5$ t/w vs. $<5$ t/w (ref.) & $0.24(0.08-0.76)^{*}$ & $2.45(0.88-6.83)$ \\
\hline Pizza & $\geq 2$ t/w vs. 2 t/w (ref.) & $0.62(0.21-1.83)$ & $1.19(0.31-4.59)$ \\
\hline \multicolumn{4}{|l|}{ Fruits } \\
\hline Fresh fruits & $\geq 2 /$ day vs. $2 /$ day (ref.) & $1.74(0.78-3.88)$ & $1.90(0.79-4.59)$ \\
\hline Fruit juices & $\geq 7$ t/w vs. $<7$ t/w (ref.) & $0.62(0.21-1.83)$ & $1.65(0.70-3.89)$ \\
\hline Canned fruits & $\geq 2 \mathrm{t} / \mathrm{w}$ vs. $<2 \mathrm{t} / \mathrm{w}$ (ref.) & $1.64(0.43-6.19)$ & $0.76(0.12-4.71)$ \\
\hline Vegetables & $\geq 2 /$ day vs. <2/day (ref.) & $1.78(0.36-8.83)$ & $1.23(0.40-3.81)$ \\
\hline Nuts & $\geq 2$ t/w vs. 2 t/w (ref.) & $0.50(0.22-1.10)$ & $1.31(0.50-3.40)$ \\
\hline Potatoes and tubercles & $\geq 2$ t/w vs. 2 t/w (ref.) & $1.74(0.79-3.88)$ & $1.36(0.57-3.26)$ \\
\hline \multicolumn{4}{|l|}{ Fats } \\
\hline Olive oil & $\geq 7$ t/w vs. $<7$ t/w (ref.) & $0.87(0.40-1.88)$ & $0.97(0.42-2.25)$ \\
\hline Others oils and fats & $\geq 2$ t/w vs. $<2$ t/w (ref.) & $0.41(0.18-0.96)^{*}$ & $0.75(0.32-1.80)$ \\
\hline \multirow[t]{3}{*}{ High fat foods } & $\geq 5$ t/w vs. $\leq 4$ t/m (ref.) & $0.72(0.28-1.86)$ & $0.49(0.15-1.64)$ \\
\hline & $2-4$ t/w vs. $\leq 4$ t/m (ref.) & $1.50(0.61-3.74)$ & $0.76(0.28-2.04)$ \\
\hline & $\leq 4 \mathrm{t} / \mathrm{m}$ (ref.) & & \\
\hline \multicolumn{4}{|l|}{ Drinks } \\
\hline \multirow[t]{3}{*}{ Soft drinks } & $\geq 5$ t/w vs. $\leq 4$ t/m (ref.) & $0.43(0.18-1.02)$ & $1.46(0.62-3.46)$ \\
\hline & $2-4$ t/w vs. $\leq 4$ t/m (ref.) & $0.52(0.15-1.77)$ & $0.33(0.04-2.87)$ \\
\hline & $\leq 4 \mathrm{t} / \mathrm{m}$ (ref.) & & \\
\hline Tea and coffee & $\geq 2$ t/w vs. 2 t/w (ref.) & $2.14(0.65-7.11)$ & $0.74(0.24-2.26)$ \\
\hline Alcoholic beverages & $\geq 1 \mathrm{t} / \mathrm{w}$ vs. $<1 \mathrm{t} / \mathrm{w}$ (ref.) & $0.79(0.19-3.20)$ & $3.32(0.44-25.29)$ \\
\hline \multicolumn{4}{|l|}{ Sweet } \\
\hline \multirow[t]{2}{*}{ Sweets } & $\geq 5$ t/w vs. $\leq 4 \mathrm{t} / \mathrm{m}$ (ref.) & $2.64(0.71-9.77)$ & $1.01(0.30-3.42)$ \\
\hline & $2-4$ t/w vs. $\leq 4$ t/m (ref.) & $1.36(0.30-6.06)$ & $1.38(0.37-5.17)$ \\
\hline
\end{tabular}


Table 5 Association between body image and food consumption among adolescents (Continued)

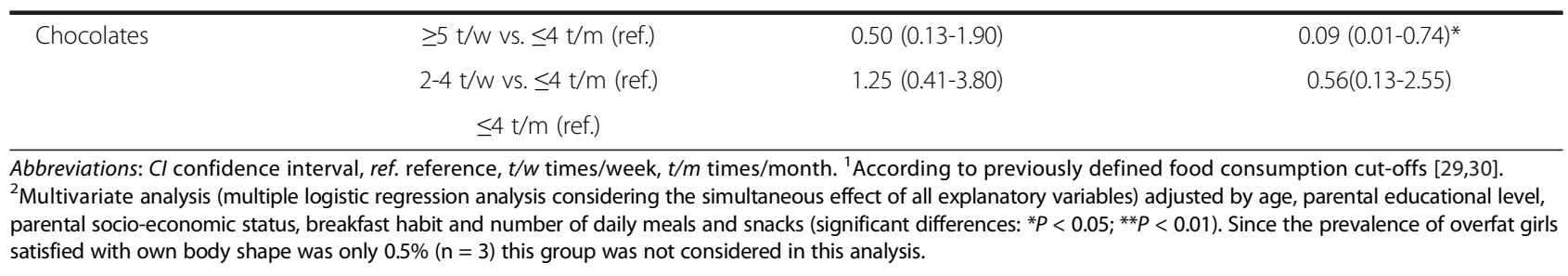

BMI is positively related to body dissatisfaction [43-45]. However, in the present study, the association between body image and food consumption patterns according to body composition has been demonstrated. Thirdly, the use of BMI for age to define being overweight and obesity in children and adolescents is well established for both clinical and public health applications $[54,55]$. However, it has been recognized that elevation of BMI does not always equate to increased adiposity because it does not distinguish between BF mass and lean body mass [56], whereas the FMI has a high accuracy level for overweight screening [23]. Accordingly, after several statistically known potential confounding factors were controlled in this study, the adolescent population was classified according to both BMI and FMI, as it has been published elsewhere [57].

\section{Competing interests}

The authors declare that they have no competing interests.

\section{Authors' contributions}

$M M B, J P$ and JAT conceived, designed, devised and supervised the study, $M M B, J P$ and JAT collected and supervised the samples. MMB and JAT analysed the data and wrote the manuscript. AP and JAT obtained funding. All authors read and approved the final manuscript.

\section{Funding sources}

The study was supported by the Spanish Ministry of Health and Consumption Affairs (Programme of Promotion of Biomedical Research and Health Sciences, Projects 05/1276, 08/1259, and 11/01791, Red Predimed-RETIC RD06/0045/1004, and CIBERobn CB12/03/30038), Grant of support to research groups no. 35/ 2011 (Balearic Islands Gov. and EU FEDER funds), Spanish Ministry of Education and Science (FPU Programme, PhD fellowship to M.M.B.). The Research Group on Community Nutrition and Oxidative Stress, University of Balearic Islands belongs to the Centre Català de la Nutrició (IEC) and Exernet Network.

Received: 2 May 2013 Accepted: 27 November 2013

Published: 1 December 2013

\section{References}

1. Ebbeling CB, Pawlak DB, Ludwig DS: Childhood obesity: public-health crisis, common sense cure. Lancet 2002, 360:473-482.

2. Dehghan M, Akhtar-Danesh N, Merchant AT: Childhood obesity, prevalence and prevention. Nutr J 2005, 4:24.

3. Bibiloni MM, Martinez E, Llull R, Juarez MD, Pons A, Tur JA: Prevalence and risk factors for obesity in Balearic Islands adolescents. Brit J Nutr 2010, 103:99-106

4. Bibiloni MM, Martínez E, Llull R, Maffiotte E, Riesco M, Llompart I, Pons A, Tur JA: Metabolic syndrome in adolescents in the Balearic Islands, a Mediterranean region. NutrMetabo/Cardiov Dis 2011, 21:446-454.
5. Cuenca-García M, Ortega FB, Ruiz JR, et al: Combined influence of healthy diet and active lifestyle on cardiovascular disease risk factors in adolescents. Scand J Med Sci Sports 2012. doi:10.1111/sms.12022.

6. Cuenca-García M, Huybrechts I, Ruiz JR, et al: Clustering of multiple lifestyle behaviors and health-related fitness in European adolescents. J NutrEducBehav 2013. doi:10.1016/.jneb.2013.02.006.

7. Beech BM, Rice R, Myers L, Johnson C, Nicklas TA: Knowledge, attitudes, and practices related to fruit and vegetable consumption of high school students. J Adol Health 1999, 24:244-250.

8. Vyncke KE, Libuda L, De Vriendt T, et al: Dietary fatty acid intake, its food sources and determinants in European adolescents: the HELENA (Healthy Lifestyle in Europe by Nutrition in Adolescence) Study. Br J Nutr 2012, 108:2261-2273.

9. Diethelm K, Jankovic N, Moreno LA, et al: Food intake of European adolescents in the light of different food-based dietary guidelines: results of the HELENA (Healthy Lifestyle in Europe by Nutrition in Adolescence) Study. Public Health Nutr 2012, 15:386-398.

10. Llull R, Bibiloni MM, Martínez E, Pons A, Tur JA: Compliance with the 2010 nutritional objectives for the Spanish population in the Balearic Islands' adolescents. Ann NutrMetabol 2011, 58:212-219.

11. Tur JA, Serra-Majem L, Romaguera D, Pons A: Profile of overweight and obese people in a Mediterranean region. Obes Res 2005, 13:527-536.

12. Middleman $A B$, Vazquez I, Durant RH: Eating patterns, physical activity, and attempts to change weight among adolescents. J Adol Health 1998, 22:37-42.

13. Field $A E$, Austin $S B$, Taylor $C B$, et al: Relation between dieting and weight change among preadolescents and adolescents. Pediatrics 2003, 112:900-906.

14. Millstein RA, Carlson SA, Fulton JE, Galuska DA, Zhang J, Blanck HM, et al: Relationships between body size satisfaction and weight control practices among US adults. Medscape J Med 2008, 10:119.

15. Puig MS, Tur JA, Prieto RM, Benito E: Self-reported and measured overweight and weight control practices of adolescents living in a mediterranean city of Spain. Appetite 1996, 26:301.

16. Neumark-Sztainer D, Paxton SJ, Hannan PJ, Haines J, Story M: Does body satisfaction matter? Five-year longitudinal associations between body satisfaction and health behaviors in adolescent females and males. J Adol Health 2006, 39:244-251.

17. Carraça EV, Silva MN, Markland D: Body image change and improved eating self-regulation in a weight management intervention in women. Int I BehavNutrPhys Act 2011, 8:75.

18. Moreno LA, Fleta J, Mur L, Feja C, Sarría A, Bueno M: Indices of body fat distribution in Spanish children aged 4.0 to 14.9 years. J PediatrGastroentero/Nutr 1997, 25:175-181.

19. Slaughter MH, Lohman TG, Boileau RA, Horswill CA, Stillman RJ, van Loan MD, et al: Skinfold equations for estimation of body fatness in children and youths. Human Biol 1988, 60:70-23.

20. Rodríguez G, Moreno LA, Blay MG, Blay VA, Fleta J, Sarría A, et al: Body fat measurement in adolescents: comparison of skinfold thickness equations with dual-energy X-ray absorptiometry. Eur J ClinNutr 2005, 59:1158-1166.

21. International Association for the Study of Obesity (IASO): http://www.iaso. org/resources/aboutobesity/child-obesity/newchildcutoffs/. Accessed December 05, 2013.

22. Cole TJ, Bellizzi MC, Flegal KM, Dietz WH: Establishing a standard definition for child overweight and obesity worldwide: international survey. Brit Med J 2000, 320:1240-1243. 
23. Alvero-Cruz JR, Alvarez-Carnero E, Fernández-García JC, Barrera-Expósito J, de Carrillo Albornoz Gil M, Sardinha LB: Validity of body mass index and fat mass index as indicators of overweight status in Spanish adolescents: Esccola Study. Med Clin (Barc) 2010, 135:8-14.

24. Stunkard AJ, Sorensen T, Schulsinger F: Use of the Danish Adoption Register for the study of obesity and thinness. Res Publ Assoc Res Nerv Mental Dis 1983, 60:115-120.

25. Bulik CM, Wade TD, Heath AC, Martin NG, Stunkard AJ, Eaves LJ: Relating body mass index to figural stimuli: population-based normative data for Caucasians. Int J Obes 2001, 25:1517-1524.

26. Baptiste-Roberts K, Gary TL, Bone LR, Hill MN, Brancati FL: Perceived body image among African Americans with type 2 diabetes. Pat Educ Counsel 2006, 60:194-200

27. Martin-Moreno JM, Boyle P, Gorgojo L, Maisonneuve P, Fernandez-Rodriguez JC, Salvini S, et al: Development and validation of a food frequency questionnaire in Spain. Int J Epidemiol 1993, 22:512-519.

28. Gómez C, Kohen VL, Nogueira TL: Guía visual de alimentos y raciones. Madrid: EDIMSA; 2007.

29. Lazarou C, Panagiotakos DB, Matalas AL: Level of adherence to the Mediterranean diet among children from Cyprus: the CYKIDS study. Pub Health Nutr 2009, 12:991-1000.

30. Lazarou C, Panagiotakos DB, Kouta C, Matalas AL: Dietary and other lifestyle characteristics of Cypriot school children: results from the nationwide CYKIDS study. BMC Pub Health 2009, 9:147.

31. Mataix J, Mañas M, Llopis J, de Martínez Victoria E, Juan J, Borregón A: Tablas de composición de alimentos españoles. 4th edition. Granada: INTA-Universidad de Granada; 2004

32. Ortega RM, López AM, Requejo AM, Andrés P: La composición de los alimentos. Herramientabásicapara la valoraciónnutricional. Madrid: Ed. Complutense; 2004.

33. Feinberg M, Favier JC, Ireland-Ripert J: Répertoire géneral des aliments. Tec and Doc Lavoisier: París; 1995.

34. Ripoll L: La cocina de las Islas Baleares. 5th edition. Palma de Mallorca: L. Ripoll Pub. Co.; 1992

35. Livingstone MBE, Black AE: Biomarkers of nutritional exposure and nutritional status. J Nutr 2005, 133:895S-920S.

36. Johansson L, Solvoll K, Bjørneboe GA, Drevon CA: Under- and overreporting of energy intake related to weight status and lifestyle in a nationwide sample. Am J ClinNutr 1998, 68:266-274.

37. Alvarez C, Alonso J, Domingo A, Regidor E: La medición de la clase social en ciencias de la salud. Barcelona: SG-Sociedad Española de Epidemiología; 1995.

38. Nowak M: The weight-conscious adolescent: Body image, food intake, and weight-related behaviour. J Adol Health 1998, 23:389-398.

39. Arora M, Nazar GP, Gupta VK, et al: Association of breakfast intake with obesity, dietary and physical activity behaviour among urban schoolaged adolescents in Delhi, India: results of a cross-sectional study. BMC Pub Health 2012, 12:881

40. Chang YJ, Lin W, Wong Y: Survey on eating disorder-related thoughts, behaviours, and their relationship with food intake and nutritional status in female high school students in Taiwan. J Am CollNutr 2011, 30:39-48.

41. Zaborskis A, Petronyte G, Sumskas L, Kuzman M, lannotti RJ: Body image and weight control among adolescents in Lithuania, Croatia, and the United States in the context of global obesity. Croatian Med J 2008, 49:233-242.

42. Hargreaves DA, Tiggermann M: Idealized media images and adolescent body image: "comparing" boys and girls. Body image 2004, 1:351-361.

43. Khor GL, Zalilah MS, Phan YY, Ang M, Maznah B, Norimah AK: Perceptions of body image among Malaysian male and female adolescents. Singapore Med J 2009, 50:303-311.

44. Jones DC, Crawford JK: Adolescent boys and body image: weight and muscularity concerns as dual pathways to body dissatisfaction. $J$ Youth Adol 2005, 34:629-636.

45. O'Haver J, Melnyk BM, Mays MZ, Kelly S, Jacobson D: The relationship of perceived and actual weight in minority adolescents. J Pediat Nursing 2009, 24:474-480

46. Al-Sendi AM, Shetty P, Musaiger AO: Body weight perception among Bahraini adolescents. Care, Health Develop 2004, 30:369-376.

47. Cash TF, Morrow JA, Hrabosky Jl, Perry AA: How has body image changed? A cross-sectional investigation of collegue women and men from 1993 to 2001. J Consult ClinPsychol 2004, 72:1081-1089.
48. Wright MR: Body image satisfaction in adolescent girls and boys. A longitudinal study. J Youth Ado/ 1989, 18:71-83.

49. Meland E, Haugland S, Breidablik HJ: Body image and perceived health in adolescence. Health Educ Res 2007, 22:342-350.

50. Heinberg L: Body image dissatisfaction as a motivator for healthy lifestyle change: is some distress beneficial? Washington DC: American Psychological Association; 2001.

51. Wang $Y$, Liang $H$, Chen $X$ : Measured body mass index, body weight perception, dissatisfaction and control practices in urban, low-income African American adolescents. BMC Pub Health 2009, 9:183-194.

52. Bibiloni MM, Martinez E, Llull R, Pons A, Tur JA: Western and Mediterranean dietary patterns among Balearic Island's adolescents: socio-economic and lifestyle determinants. Pub Health Nutr 2012, 15:683-692.

53. Monge-Rojas R, Nuñez HP, Garita C, Chen-Mok M: Psychosocial aspects of Costa Rican adolescents' eating and physical activity patterns. J Adol Health 2002, 31:212-219.

54. Must A, Anderson SE: Body mass index in children and adolescents: considerations for population-based applications. Int J Obes 2006, 30:590-594

55. Reilly JJ: Diagnostic accuracy of the BMI for age in paediatrics. Int J Obes 2006, 30:595-597.

56. Chan RS, Woo J: Prevention of overweight and obesity: how effective is the current public health approach. Int J Environ Res Pub Health 2010 7:765-783.

57. Bibiloni MM, Pons A, Tur JA: Defining body fatness in adolescents: a proposal of the AFAD-A classification. PLoS One 2013, 8:e55849.

doi:10.1186/1471-2458-13-1104

Cite this article as: Bibiloni et al:: Body image and eating patterns among adolescents. BMC Public Health 2013 13:1104.

\section{Submit your next manuscript to BioMed Central and take full advantage of:}

- Convenient online submission

- Thorough peer review

- No space constraints or color figure charges

- Immediate publication on acceptance

- Inclusion in PubMed, CAS, Scopus and Google Scholar

- Research which is freely available for redistribution

Submit your manuscript at www.biomedcentral.com/submit
C) Biomed Central 